\title{
ECOLOGICAL QUALITY OF FRESHWATER LAKES AND THEIR MANAGEMENT APPLICATIONS IN URBAN TERRITORY
}

\author{
Oskars Purmalis, Linards Kḷaviņšs, Lauris Arbidans \\ University of Latvia, Latvia \\ oskars.purmalis@lu.lv
}

\begin{abstract}
Freshwater lakes and rivers are habitats of variety of organisms and their populations giving great importance for freshwater ecosystems and providing water resources, food and recreational possibilities for humans. In spite of their fundamental importance to humans, freshwater lakes have been affected by anthropogenic disturbances, which have led to serious negative effects on the structure, functions and quality of these ecosystems. Lake ecosystems are dependent on inflow of water and supply of matter and energy from their catchment area. In studied lakes significant anthropogenic impact in loads of nutrients in their sediments and water was detected. This highlights the well-known problem of freshwaters in the World and in Europe - eutrophication, which can lead to increased productivity of water ecosystems - increased algae blooms, spreading of macrophytes and decreasing of oxygen content in water. Studied lake ecosystems show presence of human impact, not only by physiochemical parameters, but also by changes in biomass production, cyanobacterial algal blooms and overgrowing with macrophytes was observed. In order to improve water quality, appropriate management measures should be applied. We have analysed advantages and disadvantages of such measures as sediment removal, constructing of wetlands, cutting reeds and forming ecotones.
\end{abstract} Key words: water quality, nutrient loads, lake ecosystems, eutrophication.

\section{Introduction}

Lakes are ecosystems that are localized in a basin, usually with rivers or channels feeding or draining it (Hairston et al., 2014). Relation between physical, biogeochemical and organismal processes in lakes can be studied to understand overall ecosystem quality and choose effective management. In the lake management, without conserving natural process, it is also important to employ existing and potential ecosystem services (Cramer, 2008; Hassall, 2014). Human activity can strongly influence aquatic ecosystems, and some activities have dramatically altered the fluxes of growth-limiting nutrients from the catchment area. Elevated availability of nutrients had negative effects to the quality of surface waters worldwide, indicating eutrophication (Smith, 2003). Eutrophication of water bodies leads to significant changes in the functions and quality of the aquatic ecosystems. Water bodies, which have been described to have strong eutrophication are usually surrounded by densely populated human settlements, agricultural lands with runoff containing nutrients used for fertilization, sewage drains which feed phosphorus used in household detergents etc. (Khan et al., 2005; Sorrano et al., 2015). Eutrophication causes predictable increases in the biomass of algae in waterbodies responding to changes in nutrient loadings and suspended material form catchment area (Smith, 2003). During algae blooms cyanobacterial dominance of phytoplankton has been reported, as well as similar trends of different types of waterbodies have been reported worldwide (Smith, 2003; Paerl et al., 2011). Experiments with $\mathrm{N}$ and $\mathrm{P}$ show importance of both of the nutrients (Klavins et al., 2002), but reduced nitrogen inputs in comparison to phosphorus may lead to growth of nitrogen-fixing cyanobacteria (Schindler et al., 2008). Without discussed eutrophication processes, effective management measures and restoration methods are important, also related to possible effects with climate change. Analysis of literature shows that the increase of temperature will affect the physical, chemical, and biological properties of lake ecosystems (Kḷaviņš et al., 2008). These changes will lead to decrease in water quality (with likely increased abundance of noxious cyanobacteria) and for wildlife habitats (with changes in stratification regimes and primary production) (Brönmark et al., 2002; Vincent, 2009). Although it is expected that in northern lakes and rivers, productivity of water ecosystems may increase, but it will also have increased risks due to changes in water levels in the case of warming and periods of dry conditions (Cramer, 2008). Eutrophication induced increase of biomass production in waterbodies can lead to decrease of water depth, especially in dry conditions and if the hydrological regimes are changed. This may influence food chain in lakes, as suggested by a biomanipulation concept, where phytoplankton is eaten by zooplankton, which is then eaten by planktivorous fish, which, in turn, are eaten by piscivorous fish (Hansson et al., 2009). Typically, in water ecosystems where algae blooms occur the amount of zooplankton communities and predator fish is decreased and they have even more difficulties to hunt in these waters (low visibility) (Brönmark et al., 2002; Hansson et al., 2009). The trophic levels play important role in waterbodies (Hansson et al., 2009), but also the amount of macrophytes (also submerged) should be taken into account, due resuspension of particles from the sediment ( $\mathrm{P}$ cycling 
and decreased light penetration), and internal loads of nutrients. Two lakes in Latvia which coastline is urbanized and are inter-connected were studied. The aim of the following work is to characterize water quality, ecosystem functionality and analyse possible management actions.

\section{Materials and Methods}

Lake Balvu and Lake Pērkonu (Figure 1) is located in NE Latvia. Sampling points (in 2018) (Table 1) cover both lakes and rivers. Lakes are of Pleistocene glacial origin, they are connected and outflowing, indicating strong sedimentation rates in the particular watershed basin.

Sampling

The sampling of water was carried out in the $1 \mathrm{~L}$ PET bottle and stored in a cold storage. Some of the physico-chemical characteristics of water including water temperature, $\mathrm{pH}$, dissolved oxygen were determined using HACH HQ40 portable multimeter.

Sampling of sediment cores, for analysis of nutrients $(\mathrm{N}, \mathrm{P})$, was performed in the central part of the lakes. Coring of sediments was done using a sediment sampler equipped with a $1.0 \mathrm{~m}$ long $(\mathrm{d}=5 \mathrm{~cm})$ tube. Every sample was put into a nontransparent airtight plastic bucket with a lid and stored at constant temperature $\left(+4{ }^{\circ} \mathrm{C}\right)$ to achieve in situ conditions during the storage. Sediments were dried at $105{ }^{\circ} \mathrm{C}$ before digestion.

Phytoplankton

Quantitative phytoplankton samples were fixed with $1 \%$ acidified Lugol's iodine solution. Phytoplankton counts were performed using LEICA DMI3000 inverted microscope. Individual biovolumes

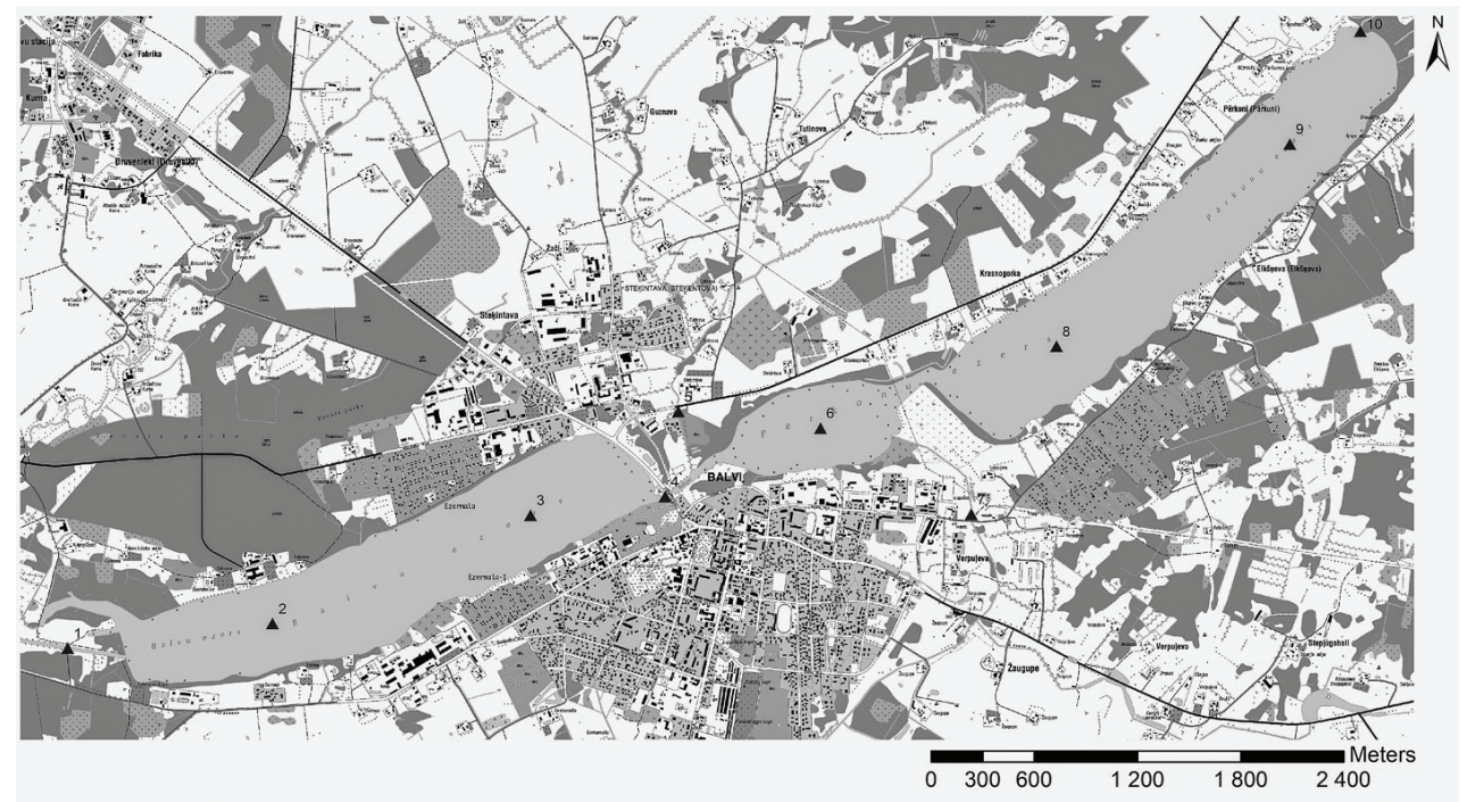

Figure 1. Location of sampling sites (1-10) in Balvu and Pērkonu Lakes.

Table 1

Sampling points in Lake Balvu and Lake Pērkonu

\begin{tabular}{|c|c|c|}
\hline Sampling point No. & Latitude & Longitude \\
\hline 1 & 57.1277601 & 27.2058369 \\
\hline 2 & 57.1289345 & 27.2259225 \\
\hline 3 & 57.1343296 & 27.2498675 \\
\hline 4 & 57.1345481 & 27.2615253 \\
\hline 5 & 57.1382042 & 27.2630045 \\
\hline 6 & 57.1372179 & 27.2766900 \\
\hline 7 & 57.1337174 & 27.2904518 \\
\hline 8 & 57.1412682 & 27.3000351 \\
\hline 9 & 57.1511599 & 27.3230471 \\
\hline 10 & 57.1563993 & 27.3302171 \\
\hline
\end{tabular}


were calculated using appropriate geometric formulae according to their shapes and the mean dimensions of the organisms in the samples (Hillebrand et al., 1999). Biomass was estimated from biovolume, assuming unit specific gravity (APHA, 2005).

Nitrogen determination in lake sediments.

Approximately 0.5 grams of dry sample was transferred to a $250 \mathrm{~mL}$ digestion flask and $4 \mathrm{~mL}$ of $2.5 \%$ salicylic acid in sulfuric acid was added to the sample. The sample was left for 4 hours and afterwards was digested in a Kjeldahl digestion unit (behr Labor-Technik behrotest ${ }^{\circledR}$ K-12). After digestion $20 \mathrm{~mL}$ of distilled water was added to the sample to make a suspension. Afterwards the samples were distilled in a Kjeldahl distillation unit (behr LaborTechnik behrotest $\left.{ }^{\circledR} \mathrm{S} 1\right), 25 \mathrm{~mL}$ of boric acid solution ( $c=20 \mathrm{~g} \mathrm{~L}^{-1}$ ) was added to the distilled sample, 5 drops of methylred indicator was added and sample was titrated with $0.01 \mathrm{M} \mathrm{H}_{2} \mathrm{SO}_{4}$.

Phosphorus determination in lake sediments.

Sediments were dried at $105{ }^{\circ} \mathrm{C}$ before digestion. Approximately $500 \mathrm{mg}$ of sample was weighed in a Teflon capsule and $9 \mathrm{~mL}$ of concentrated $\mathrm{HNO}_{3}$ and $1 \mathrm{~mL}$ of $30 \% \mathrm{H}_{2} \mathrm{O}_{2}$ was added to the sample. The capsule was sealed and placed in a microwave oven (Milestone Ethos Easy) and was digested at $200{ }^{\circ} \mathrm{C}$ and 49 bar pressure for 15 minutes. After digestion the sample was filtered through a filter paper, diluted up to $50 \mathrm{~mL}$ with distilled water and phosphorus concentration was determined with ICP-OES (Thermo Scientific iCAP 7000 series).

Determination of total nitrogen concentration in water

Total nitrogen was determined using a standardized Hach ${ }^{\circledR}$ Method 10071. One Total Nitrogen Persulphate Powder Pillow was added to each of two Total Nitrogen
Hydroxide Reagent vials, $2 \mathrm{~mL}$ of sample was added to one vial, and $2 \mathrm{~mL}$ of distilled water was added to the other. Both vials were vigorously shaken for 30 seconds. Both the sample and blank were placed in a COD reactor for 30 minutes at $105^{\circ} \mathrm{C}$. Total Nitrogen Reagent A Powder Pillow was added to both sample and blank, the tubes were then shaken for 15 seconds. After 3 minutes Total Nitrogen Reagent B Powder was added to the sample and blank, tubes were then shaken for 15 seconds. After 2 minutes $2 \mathrm{~mL}$ of digested sample and blank were transferred to TN Reagent C vials, the vials were slowly inverted approximately 10 times for a complete recovery. After 5 minutes the sample was measured at $410 \mathrm{~nm}$ wavelength on a spectrophotometer (Hach-Lange DR2800).

Determination of total phosphorus concentration in water.

Total phosphorus was determined using a standardized Hach ${ }^{\circledR}$ Method 8190 . Five $\mathrm{mL}$ of sample was pipetted in a test vial, one Total Potassium Persulphate Powder Pillow was added to the tube, shaken, and placed in a COD reactor at $150{ }^{\circ} \mathrm{C}$ and heated for 30 minutes. After digestion $2 \mathrm{~mL}$ of $1.54 N$ sodium hydroxide standard solution was added to the vial and shaken. Afterwards all the contents of one PhosVer3 powder pillow was added to the vial. The test tube was shaken for 10-15 seconds and measured after 8 minutes on a spectrophotometer (Hach-Lange DR2800).

\section{Results and Discussion}

Lake Balvu (Figure 1) is located in NE Latvia with an area $-1.68 \mathrm{~km}^{2}$ and average depth $-2.2 \mathrm{~m}$ $(\max -3.9 \mathrm{~m})$ and catchment area, including Bolupe River $-248 \mathrm{~km}^{2}$. Perkonu Lake is located in NE Latvia

Concentrations ( $\left.\mathrm{mg} \mathrm{l}^{-1}\right)$ of nutrients $(\mathrm{N}, \mathrm{P})$ in Lakes Balvu and Pērkonu

Table 2

\begin{tabular}{|c|c|c|c|c|c|c|c|c|c|c|}
\hline \multirow[b]{2}{*}{$\begin{array}{l}\text { Sampling } \\
\text { point No. }\end{array}$} & \multicolumn{2}{|c|}{ March } & \multicolumn{2}{|c|}{ May } & \multicolumn{2}{|c|}{ July } & \multicolumn{2}{|c|}{ September } & \multicolumn{2}{|c|}{ November } \\
\hline & $\begin{array}{c}\mathrm{N}, \mathrm{mg} \\
\mathrm{l}^{-1}\end{array}$ & $\mathrm{P}, \mathrm{mg} \mathrm{l}^{-1}$ & $\begin{array}{c}\mathrm{N}, \mathrm{mg} \\
\mathrm{l}^{-1}\end{array}$ & $\mathrm{P}, \mathrm{mg} \mathrm{l}^{-1}$ & $\begin{array}{c}\mathrm{N}, \mathrm{mg} \\
\mathrm{l}^{-1}\end{array}$ & $\mathrm{P}, \mathrm{mg} \mathrm{l}^{-1}$ & $\mathrm{~N}, \mathrm{mg} \mathrm{l}^{-1}$ & $\mathrm{P}, \mathrm{mg} \mathrm{l}^{-1}$ & $\begin{array}{c}\mathrm{N}, \mathrm{mg} \\
\mathrm{1}^{-1}\end{array}$ & $\mathrm{P}, \mathrm{mg} \mathrm{l}^{-1}$ \\
\hline 1 & 0.88 & 0.089 & 0.65 & 0.070 & 3.43 & 0.233 & 2.11 & 0.089 & 0.97 & 0.071 \\
\hline 2 & 0.9 & 0.071 & 0.62 & 0.062 & 2.85 & 0.161 & 1.34 & 0.126 & 0.91 & 0.103 \\
\hline 3 & 0.85 & 0.094 & 1.08 & 0.068 & 1.48 & 0.21 & 1.39 & 0.102 & 0.92 & 0.116 \\
\hline 4 & 1.00 & 0.086 & 0.79 & 0.069 & 1.07 & 0.109 & 2.13 & 0.109 & 0.83 & 0.084 \\
\hline 5 & 0.95 & 0.071 & 1.15 & 0.13 & 0.88 & 0.392 & 0.437 & 0.118 & 0.9 & 0.136 \\
\hline 6 & 1.16 & 0.092 & 0.86 & 0.069 & 1.07 & 0.417 & 1.05 & 0.076 & 0.94 & 0.103 \\
\hline 7 & 1.39 & 0.085 & 1.20 & 0.105 & 0.82 & 0.256 & 0.508 & 0.083 & 1.94 & 0.144 \\
\hline 8 & 1.11 & 0.092 & 0.93 & 0.07 & 1.05 & 0.154 & 1.12 & 0.082 & 0.87 & 0.064 \\
\hline 9 & 1.04 & 0.093 & 0.70 & 0.116 & 0.91 & 0.179 & 1.06 & 0.089 & 0.8 & 0.067 \\
\hline 10 & 0.87 & 0.085 & 1.27 & 0.13 & 1.04 & 0.464 & 1.13 & 0.079 & 1.28 & 0.076 \\
\hline
\end{tabular}




\section{Element composition and their relations of sediments in Lakes Balvu and Lake Pērkonu}

\begin{tabular}{|c|c|c|c|}
\hline Sampling point No. & $\mathrm{N}, \%$ & $\mathrm{P}, \mathrm{g}$ kg-1 & $\mathrm{N}: \mathrm{P}$ \\
\hline 9 & 1.08 & 0.99 & $11: 1$ \\
\hline 8 & 1.20 & 1.21 & $10: 1$ \\
\hline 6 & 1.43 & 0.96 & $15: 1$ \\
\hline 3 & 0.59 & 0.90 & $7: 1$ \\
\hline 2 & 0.91 & 1.29 & $7: 1$ \\
\hline
\end{tabular}

with an area $-2.28 \mathrm{~km}^{2}$ and average depth $-1.3 \mathrm{~m}$ (max $-3.0 \mathrm{~m}$ ) with catchment area, including Bolupe River $-237.4 \mathrm{~km}^{2}$ This hydrological system starts with Bolupe River which flows into Lake Pērkonu with average annual flow rate $(\mathrm{Q})-1.17 \mathrm{~m}^{3} \mathrm{~s}^{-1}$. Between both lakes there is a small extension of Lake Perkonu where River Žaugupe and River Pelnupe carries their water with average annual flow rate (Q) $0.10 \mathrm{~m}^{3} \mathrm{~s}^{-1}$ and $0.12 \mathrm{~m}^{3} \mathrm{~s}^{-1}$, respectively. Tributaries with increased total catchment area lead to an increased flow from Lake Perkonu to Lake Balvu with in comparison to Bolupe River, with average annual flow rate $1.50 \mathrm{~m}^{3} \mathrm{~s}^{-1}$. Finally, on Lake Balvu water locks with an average annual flow rate $1.57 \mathrm{~m}^{3} \mathrm{~s}^{-1}$ are installed. This data shows that the water quality in Lake Balvu is dependent on the quality of Lake Pērkonu. Urbanized coastal area of both lakes and, especially of Lake Balvu can be influenced by anthropogenic factors (surface runoff, presence of sewage etc.). In the 60-ies of last century hydrological regime of Bolupe River was changed which lead to decreased water level of studied exoreic lakes by $1.5 \mathrm{~m}$.

Analysed concentrations, distribution and seasonal changes of chemical ingredients indicate a strong impact of anthropogenic loads. The major problems of eutrophication in studied lakes are availability of phosphorus, lack of oxygen in winter and blooms of cyanobacteria in summer. Concentrations of nutrients
(N,P) in Balvu and Pērkonu Lakes have similar seasonal pattern as other surface waterbodies in Latvia (Kḷviņš et al., 2002). Data shows big loads of nutrients from catchment area (tributaries of lakes), especially with $\mathrm{P}$ (Table 2; Figure 2). Although nutrients are important to provide biological processes in surface waters (Klavin̄š et al., 2002; Kḷavinšs et al., 2011), reduced $\mathrm{N}$ inputs in studied lakes in comparison to $\mathrm{P}$ can lead to increased amount of nitrogen-fixing cyanobacteria as a response by the phytoplankton community to extreme seasonal nitrogen limitation and availability of $\mathrm{P}$ (Schindler et al., 2008). This phenomenon correlates with phytoplankton communities, where in Lake Balvu $89 \%$ of phytoplankton biomass consists of blue-green algae (Cyanophyceae), which is also described as important $\mathrm{N}$ fixing algae (Aphanizomenon flosaquae) (Beversdorf et al., 2013; Li et al., 2018). In Lake Perkonu, these algae are in small concentrations, but in extension of Pērkonu Lake increases to $30 \%$ of phytoplankton biomass. This can be as a response to loads of nutrients from Žaugupe and Pelnupe Rivers in this particular area as well as the low average depth of this extension which is less than $1 \mathrm{~m}$.

One of key factors to describe loads of nutrients is also their ratio. In surface waterbodies, N:P ratio above 12 indicate P-limitation, while below $12 \mathrm{~N}$-limitation accordingly (Kḷaviņš et al., 2002; Sterner, 2011). Analysis of N:P ratio shows seasonal changes, and

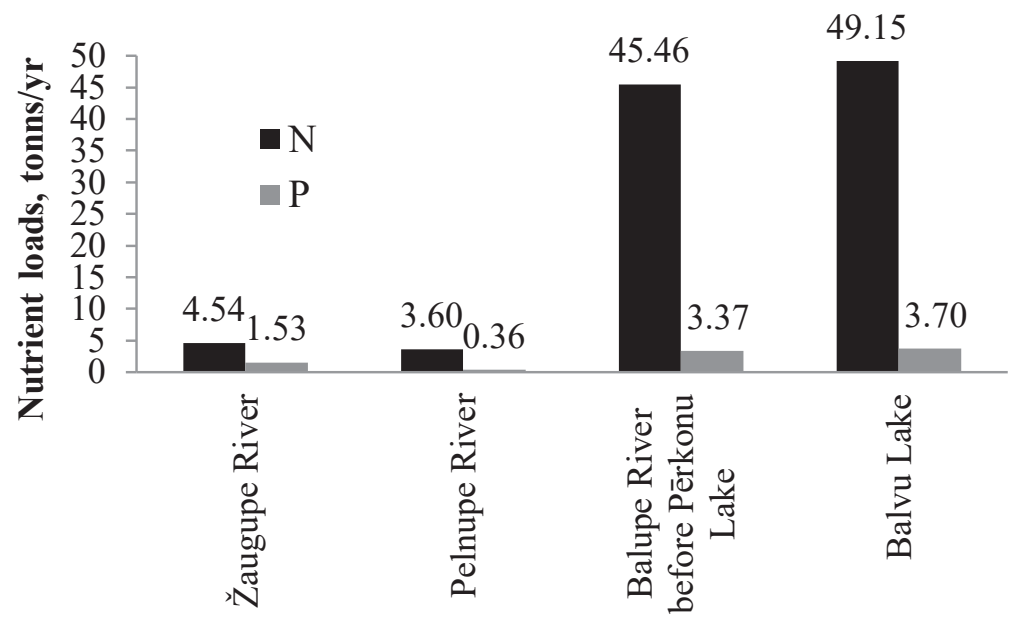

Figure 2. Estimated cumulative amount of nutrient flows in Lake Balvu and Lake Pērkonu. 
in winter time it ranges from 9.04 to 16.35 with lowest values in Lake Balvu and in River Bolupe. The pattern of this ratio change, when nutrients are consumed by the producers of biomass, shows that in most cases $\mathrm{N}$ is the factor that limits the possible production of biomass. All tributaries indicate big $\mathrm{P}$ loads peaking in July despite the fact that nutrients are also actively used (N:P 2.24-17.70). Autumn season demonstrates an increase of N:P ratio, but it mostly happens because of dominated destruction and sedimentation processes in freshwater ecosystems. Lake Pērkonu is the first waterbody with slower water flow; therefore, first sedimentation processes dominate and can be evaluated by average depth of lakes and depth of accumulated sediments. Increased concentrations of nutrients, impact form urban areas and possibly warmer water which flows into Balvu Lake lead to even higher eutrophication acceleration. Increased eutrophication may lead to not only algae blooms, but also to overgrowing with macrophytes. Analysis of macrophyte coverage shows 15\% for Lake Balvu, while Lake Perkonu coverage reaches $50 \%$. These differences also can be explained with an average depth of lakes. Differences of approximately calculated loads (Figure 2) of nutrients show that the major part comes from tributaries of Lake Pērkonu. In Lake Balvu calculated loads from water flows show no or insignificant loads from the coastal area of this lake. A relatively small increase in nutrients in Balvu Lake also can be connected with previously described $\mathrm{N}$ fixing with biota, but loads from coastal area could not be seen in an outflow stream because of sedimentation processes in the lake. Also, there can be loads of nutrients with atmospheric deposition.

To better describe processes in studied lakes, also sediment analyses were done, including $\mathrm{N}, \mathrm{P}$ concentrations in the upper sediment layer (Table 3). Upper layers of studied lakes indicate a strong impact of human actions in watershed basin and in coastal area of lakes with significantly increased proportion of allochthonous material (Purmalis et al., 2017). High $\mathrm{N}: \mathrm{P}$ ratios typically are associated with agricultural runoff (Lanza-Espino et al., 2015), which correlates very well also with Lake Balvu and Pērkonu and their location in the studied hydrological cycle and catchment area. The upper part of sediments by $\mathrm{N}: \mathrm{P}$ ratio in Lake Balvu significantly differs from Lake Pērkonu demonstrating that actual sources of sediments can be plankton and material carried from the coastal area and Lake Pērkonu whereas in last decades in Lake Pērkonu sediments are formed form allochthonous material and also partly form autochthonous material.

Lake Management Measures

The obtained data shows that studied lakes are eutrophic lakes with large loads of nutrients from the catchment area. There are risks that environmental events and their changes can lead to a decrease of water quality and lake ecosystem health. Therefore, the management of lakes (Cosgrove et al., 2015) in order to reduce anthropogenic impact is needed (Burlakovs et al., 2018). Measures that can be applied are various in their positive aspects as well as consequences. Firstly, it is important to reduce loads of nutrients from the catchment area. This can occur with revising of sewage system in urbanized territory and revising of applied agricultural practice in order to reduce nutrients in surface waters in catchment area of lakes. Secondly, installing wetland constructions (Ghermandi et al., 2010) on most important nutrient sources (Bolupe, Žaugupe, Pelnupe Rivers) can reduce amount of $\mathrm{N}$ and $\mathrm{P}$ carried with rivers by $40-60 \%$ (Vymazal, 2007). Thirdly, to stabilize or reduce amount of nutrients of lakes with cutting reeds (Köbbing et al., 2013), applying solid phase P-sorption products to sediments (Spears et al., 2013; Aalto et al., 2018; Rosińska et al., 2018) or by sediment removal (Van Wichelen et al., 2007). Additional activities that can be applied are forming ecotones (Thorp et al., 2015) on the coastal area of lakes or even applying biomanipulation of trophic communities of lakes and oxygenation of water, especially in winter time and during blooms of blue-green algae (Jørgensen et al., 2005).

Advantages of revising the sewage system and applied agricultural practice could decrease annual amount of nutrients coming from the catchment area which is the most important source in studied lakes. In result, nutrients in lakes will be less available; however, success rate for these actions can be limited, because reduction of non-point sources is difficult (Schindler, 2012). Mentioned revision of these systems can be combined with constructed wetlands. Studies show (Vymazal, 2007; Ghermandi et al., 2010) that wetlands can be effectively used for removal of nutrients in water. Parameters of studied rivers (their location, flowrate) are suitable for applying wetlands. Disadvantages of this particular method are construction expenses and affected hydrological regime of streams, as well as a regular maintenance of wetlands is important. During the maintenance of wetlands collected reed biomass can be used as an energy source with possible annual biomass production $3.6-43 \mathrm{t}$ per ha $\mathrm{h}^{-1}$ (Vaičekonyte et al., 2013; Joensuu et al., 2013; Barz et al., 2013). Additional biomass for energy production can be reeds from lakes with average productivity $\sim 5 \mathrm{t}$ per ha $^{-1}$ (Komulainen et al., 2008). Reeds can accumulate nutrients to produce their biomass and when removed from the lake, nutrients will be removed from cycling. Side-effects of this method are expenses of cutting reeds in lakes (in summer) while keeping healthy lake ecosystem could be applied only on particular lake sectors in order to cut everything (Rosińska et 
al., 2017). Biomass production is connected with a vegetation period, but cutting in winter time, has less effect on removal of nutrients, because of storage of nutrients on their roots. From the energy production perspective - reed biomass harvested in winter (possible to cut all produced biomass above ice sheet), collected in vegetation season and stored for drying can be effectively used in winter time, when the demand for heat energy is the highest. Also, reeds can be used for different purposes.

Advantages of solid phase P-sorption for reducing the amount of $\mathrm{P}$ are immediate $\mathrm{P}$ removal from cycling in their way: water-sediments-water. These methods can be costly, they can reduce the depth of lake, affect or destroy benthic fauna and be as a source of chemical substances in lakes (Spears et al., 2013; Aalto et al., 2018; Rosińska et al., 2018). Therefore, more affordable (ecological scale) and more appropriate technology in studied lakes can be excavation of sediments. Excavated organic material can be used in agricultural applications (Stankevica et al., 2016) and accumulated nutrients will be removed from lake ecosystems and active element cycling. In order to keep benthic fauna, sediment removal should be done only partly (in more shallow parts of lakes and parts with high average depth of sediments, basically in both ends of Lake Pērkonu). Sediment removal applied in extension of Lake Perkonu can improve water quality and ecological status not only of Lake Pērkonu, but also Lake Balvu. Other kind of activity to reduce nutrient loads from coastal areas is forming terrestrial ecotones (Thorp et al., 2015), which can accumulate nutrients migrating to lake in order to provide their biomass production. For that purpose different plants and trees can be used, but this approach can be slow and could be difficult to evaluate real benefits. It can change also the landscape and in urban territories can be difficult to apply because of difficult harmonization with landowners of coastal area of lakes. To reduce resolving of already existing phosphorus into water from sediments in anoxic conditions, water oxygenation can be applied. This method will improve conditions in lakes in winter time as well as reduce solubilizing of $\mathrm{P}$ from sediments. The size of studied lakes could be challenging to apply oxygenation devices, but our studies indicate areas with the lowest oxygen content and can be applied more precisely, as well as movement of water masses can distribute oxygen from places where oxygenation was applied.

\section{Conclusions}

Freshwater lakes and rivers are habitats of variety of organisms and their populations are giving great importance for freshwater ecosystems, however, human actions can influence these ecosystems. In studied lakes, a significant anthropogenic impact in loads of nutrients was detected. If lakes as waterbodies are not affected by strong transformation, then other activities in their catchment area lead to decrease of their water level and accelerated eutrophication due to availability of nutrients can occur. Estimated loads of nutrients with existing water quality will not improve the lake ecological quality without appropriate management measures. Most effective measures in studied lakes could be sediment removal in certain parts of Lake Pērkonu as well as formation of wetlands on tributaries carrying highest loads of nutrients. Combining these methods with cutting reeds and revising a sewage system in urban territory (also surface runoff) may lead to improvements of water quality and decrease of algae blooms in summer time as well as improve oxygen availability in winter.

\section{Acknowledgements}

The present study was supported by the University of Latvia Effective collaboration Project 'Research of anthropogenic influence to Balvu and Pērkonu Lake ecosystems'.

\section{References}

1. Aalto, S.L., Saarenheimo, J., Ropponen, J., Juntunen, J., Rissanen, A.J., \& Tiirola, M. (2018). Sediment diffusion method improves wastewater nitrogen removal in the receiving lake sediments. Water Research, $138,312-322$.

2. APHA (2005). Standard methods for the examination of water and wastewater. $21^{\text {st }}$ Ed. American Public Health Association, APHA, AWWA, WEF, Washington, D.C. 1170 pp.

3. Barz, M., Tannenberg, F., \& Witchmann, W. (2013). Sustainable production of common reed as an energy source from wet peatlands. In: Proceedings of International conference on the utilization of emergent wetland plants 'Reed as a renewable resource', Greifswald, Germany, 90.

4. Beversdorf, L.J., Miller, T.R., \& McMahon, K.D. (2013). The role of nitrogen fixation in cyanobacterial bloom toxicity in a temperate, eutrophic lake. PloS one, 8(2), e56103.

5. Brönmark, C., \& Hansson L.A. (2002). Environmental issues in lakes and ponds: current state and perspectives. Environmental Conservation, 29(3), 290-306.

6. Burlakovs, J., Pehme, K.M., Anne, O., Kriipsalu, M., \& Hogland, W. (2018). Remarks on novel case studies for integrated pollution prevention in the Baltic Sea region. International Multidisciplinary Scientific GeoConference Surveying Geology and Mining Ecology Management, SGEM 18(3.2), 1167-1174. 
7. Cosgrove, W.J., \& Loucks, D.P. (2015). Water management: current and future challenges and research directions, Water Resour. Res., 51, 4823-4839.

8. Cramer, W. (2008). Global Change Impacts on the Biosphere. Encyclopedia of Ecology, 1736-1741.

9. de la Lanza-Espino. G., \& Soto, L.A. (2015). C:N:P Molar Ratios, Sources and ${ }^{14}$ C Dating of Surficial Sediments from the NW Slope of Cuba. PLoS ONE, 10(6), 1-19.

10. Ghermandi, A., van den Bergh, A.J.C.J. Brander, L.M., de Groot, H.L.F., \& Nunes, P.A.L.D. (2010). Values of natural and human-made wetlands: A meta-analysis. Water Resources Research, 40, W12516.

11. Hairston, N.G., \& Fussmann, G.F. (2014). Lake Ecosystems. In: John Wiley \& Sons Ltd, Chichester.

12. Hansson, L.A., \& Brönmark, C. (2009). Biomanipulation of Aquatic Ecosystems. Encyclopedia of Inland Waters, 55-60.

13. Hassall, C. (2014). The ecology and biodiversity of urban ponds. Wiley Interdisciplinary Reviews: Water, $1(2), 187-206$.

14. Hillebrand, H., Claus-Dieter, D., \& Kirschtel, D. (1999). Biovolume calculation for pelagic and benthic microalgae. J. Phycol., 35, 403-424.

15. Joensuu, I., \& Heikkilä, R. (2013). Harvesting common reed for bioenergy and to improve the condition of Northern Karelian waters. In: Proceedings of International conference on the utilization of emergent wetland plants 'Reed as a renewable resource', Greifswald, Germany, 83.

16. Jørgensen, S.E., Löffler, H., Rast, W., \& Straškraba, M. (2005). Measures for Mproving Water Quality. Developments in Water Science, 54, 169-242.

17. Khan, F.A., \& Ansari, A.A. (2005). Eutrophication: An ecological vision. The Botanical Review, 71(4), 449-482.

18. Klavins, M., Kokorite, I., Jankevica, M., Rodinovs, V., \& Dreijalte, L. (2011). Reconstruction of Anthropogenic Impact Intensity Changes during Last 300 Years in Lake Engure Using Analysis of Sedimentary Records. Environmental and Climate Technologies, 7, 66-71.

19. Klavins, M., Rodinovs, V., \& Kokorite, I. (2002). Chemistry of surface waters in Latvia. Riga, LU, Latvia, $285 \mathrm{pp}$.

20. Kḷaviņš, M., Rodinov, V., Timukhin, A., \& Kokorite, I. (2008). Patterns of river discharge: Long-term changes in Latvia and the Baltic region. Baltica, 21(1-2), 41-49.

21. Köbbing, J.F., Thevs, N., \& Zerbe, S. (2013). The utilisation of reed (Phragmites australis): a review. Mires and Peat, 13(1), 1-14.

22. Komulainen, M., Simi, P., Hagelberg, E., Ikonen, I., \& Lyytinen, S. (2008). Reed energy - Possibilities of using the common reed for energy generation in southern Finland. Turku: Turku University of Applied Sciences, Reports 67, 81 pp.

23. Li, J., Hansson, L.A., \& Persson, K.M. (2018). Nutrient Control to Prevent the Occurrence of Cyanobacterial Blooms in a Eutrophic Lake in Southern Sweden, Used for Drinking Water Supply. Water, 10, 919.

24. Paerl, H.W., Hall, N.S., \& Calandrino, E.S. (2011). Controlling harmful cyanobacterial blooms in a world experiencing anthropogenic and climatic-induced change. Science of the Total Environment, 409, 1739-1745.

25. Purmalis, O., \& Burlakovs, J. (2017). Reviving prospects for lake restoration-investigating the geochemistry of lake aluksne sediments. Research for Rural Development, 1, 145-152.

26. Rosińska, J., Kozak, A., Dondajewska, R., Kowalczewska-Madura, K., \& Gołdyn, R. (2018). Water quality response to sustainable restoration measures - Case study of urban Swarzędzkie Lake. Ecological Indicators, 84, 437-449.

27. Rosińska, J., Rybak, M., \& Gołdyn, R. (2017). Patterns of macrophyte community recovery as a result of therestoration of a shallow urban lake. Aquatic Botany, 138, 45-52.

28. Schindler, D.W. (2012). The dilemma of controlling cultural eutrophication of lakes. Proc. R. Soc. B., 279, 4322-4333.

29. Schindler, D.W., Hecky, R.E., Findlay, D.L., Stainton, M.P., Parker, B.R., Paterson, M.J., Beaty, K.G., Lyng, M., \& Kasian, S.E.M. (2008). Eutrophication of lakes cannot be controlled by reducing nitrogen input: Results of a 37-year whole-ecosystem experiment. PNAS, 105(32), 11254-11258.

30. Smith, V.H. (2003). Eutrophication of freshwater and coastal marine ecosystems a global problem. Environ Sci \& Pollut Res., 10(2), 126-139.

31. Soranno, P.A., Cheruvelil, K.S., Wagner, T., Webster, K.E., \& Bremigan, M.T. (2015). Effects of Land Use on Lake Nutrients: The Importance of Scale, Hydrologic Connectivity, and Region. Plos One, 1-22.

32. Spears, B.M., Meis, S., Anderson, A., \& Kellou, M. (2013). Comparison of phosphorus (P) removal properties of materials proposed for the control of sediment $\mathrm{p}$ release in UK lakes. Science of the Total Environment, 442, 103-110. 
33. Stankevica, K., Vincevica-Gaile, Z., \& Klavins, M. (2016). Freshwater sapropel (gyttja): Its description, properties and opportunities of use in contemporary agriculture. Agronomy Research, 14(3), 929-947.

34. Sterner, R.W. (2011). C:N:P stoichiometry in Lake Superior: freshwater sea as end member. Inland Waters, 1, 29-46.

35. Thorp, J.H. (2015). Functional Relationships of Freshwater Invertebrates. Ecology and General Biology, 65-82.

36. Vaičekonytè, R., Kiviat, E., Nsenga, F., \& Ostfeld, A. (2013). An exploration of common reed (Phragmites australis) bioenergy potential in North America. Mires and Peat, 13(12), 1-9.

37. Van Wichelen, J., Declerck, S., Muylaert, K., Hoste, I., Geenens, V., \& Vandekerkhove, J. (2007). The importance of drawdown and sediment removal for the restoration of the eutrophied shallow lake Kraenepoel (Belgium). Hydrobiologia, 584, 291-303.

38. Vincent, W.F. (2009). Effects of Climate Change on Lakes. Encyclopedia of Inland Waters, 55-60.

39. Vymazal, J. (2007). Removal of nutrients in various types of constructed wetlands. Science of the Total Environment, 380, 48-65. 